taken did not much, if at all, exceed $\alpha d r a c h m$. It was taken mixed in water, but was not completely dissolved, and the stomach was empty at the time.

I regret that $\mathrm{I}$ am unable to complete this report by adding the post-mortem appearances. Perhaps, had I been more firm, the coroner would have granted an examination of the body; but the friends had private reasons for being opposed to it, which, under the circumstances, I felt bound to respect.

Manchester, 1859.

\section{a fitror}

OF THE PRACTICE OF

\section{MEDICINE AND SURGERY IN THE}

\section{HOSPITALS OF LONDON.}

Nulla est alia pro certo noscendi via, nisi quam plurimas et morborum et dissectionum historias, tam aliorum proprias, eollectas habere et inter se comparare.-Morgagnt. De Sed. et Cans. Morb., lib. 14. Proømium.

\section{LONDON HOSPITAL.}

STRANGULATED INGUINAI HERNIA; DESCENT OF INTESTINE IN A DISTINCT SAC BEHIND A LARGE HYDROCELE.

(Under the care of Mr. Adams and Mr. Nathanied Ward.)

A strong, healthy-looking man was admitted on Jan. 9th. There was a large tumour on the right side of the scrotum, extending along the inguinal canal as far as the internal ring. There was some amount of tenderness on pressure, and the patient complained of pain across the umbilical region, and a feeling of sickness. His bowels had acted on the morning of his admission. The man mentioned that he had had the swell$\mathrm{ng}$ as long as he could remember; he had never used a truss; and, with the exception of the tumour having ${ }_{4}^{7}$ somewhat increased in size a short time before his admission, there seemed to him nothing unusual about it. He was not aware that he had strained himself in any way. On a careful examination, the tumour was found to be pyriform in shape; its narrow extremity terminated abruptly at the situation of the inner ring. The body of the swelling appeared somewhat tilted to the right side, and, for a hydrocele, was unusually prominent and tense. On the removal of the fluid by tapping the structures situated behind and internal to it appeared thickened, and there was an amount of fulness which could not be naturally accounted for. There was, however, no defined tumour, nor could impulse on coughing be detected. The symptoms of intestinal obstruction not being well marked, $\mathrm{Mr}$. Ward, who was called to the case in the first instance, recommended that an exploratory operation should be deferred, and the case carefully watched.

On the morning of the following day, the abdominal pain had increased, and vomiting had supervened, the bowels being constipated; the residual swelling had increased; and on further careful examination by Mr. Adams, it was deemed expedient to operate. The man, however, would not consent to this until the afternoon, by which time the vomiting had become stercoraceous. The patient was placed under the influence of chloroform, the sac of the hydrocele was cut through, and a small hernial tumour was exposed, the cavity of the sac of which was opened, after the outer ring had been incised. The impediment to reduction was found at the neck of the sac. This being relieved, a small knuckle of highly-inflamed intestine was reduced.

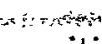

During the night, diarrhœea and vomiting set in; and the patient sank from collapse on the day following the operation, notwithstanding the free use of brandy and opium.

On a post-mortem examination, there was not found any evidence of peritonitis. The knuckle of intestine that had protruded was highly congested. The sac of the hernia was small, and situated internally to and behind the sac of the hydrocele, which latter extended upwards as far as the inner ring, in consequence of the non-obliteration of the funicular portion of the tunica vaginalis.
BLIQUE INGUINAL HERNIA IN A FEMALE; SAC ADHERENT TO GUT.

(Under the care of Mr. ADAMIs.)

The rarity of an inguinal hernia in a female renders the following case interesting:-

A spare woman, aged fifty-seven, married, was admitted on January $7 \mathrm{th}$, suffering from symptoms of strangulated inguinal hernia on the right side. The tumour was small, extending about an inch below the outer ring, and was tender to the touch. The patient appeared very weak, and her countenance had an expression as though she had been suffering much pain for a long period. Her tongue was parched and dry, and her pulse almost imperceptible. A fortnight prior to admission the bowel had descended, and she was unable to return it. The taxis was shortly after applied by a surgeon, and the greater portion of the bowel returned into the abdomen, a small tumour remaining behind in the groin. From this time she had suffered much pain about the abdomen, and almost constant retching or sickness. Her bowels had not acted. The taxis was not had recourse to after admission; but an operation, as a remote chance of saving life (considering the prostrated condition of the patient), was performed, wine having been previously administered. Mr. Adams made an incision over the external ring, which was incised. On the division of the transversalis fascia, a small quantity of blood-tinged fluid escaped, and the sac appeared to have been opened. On careful examination, however, of what appeared to be a highly congested knuckle of intestine, a thin membrane over the tumour could be pinched up between the finger and thumb. This was carefully divided with a scalpel, and turned out to be the attenuated peritoneal covering adherent by fibrin to the bowel, no fluid whatever intervening between the two. The sac was, therefore, carefully stripped away from the bowel by the aid of two forceps, and, on the division of its neck, the bowel was reduced. The finger was subsequently passed into the abdominal cavity, with the view of detecting and removing any further source of obstruction, if it existed.

The patient sank within an hour after the operation, and on a post-mortem examination the intestines were found generally healthy; there had been no peritonitis. The colon was flaccid and empty, and the bowel that had been strangulated, though much congested, was not gangrenous. The other organs of the body were healthy.

\section{ROYAL FREE HOSPITAL.}

\section{CASE OF SYPHILITIC GANGRENE OF THE MOUTH, WITH} IMPENDING SUFFOCATION.

OPERATION OF LARYNGOTOMY; RECOVERY.

(Under the care of Mr. DE MérId.

THE appearances presented by the patient in the following case for some days before impending suffocation set in, were such as to render the prognosis of the most serious kind; for the entire mouth seemed to be undergoing the sloughing process, the result of excessive ptyalism supervening some time after the cessation of the use of large doses of mercury. When we saw her in this state, it was almost an utter impossibility to get her to swallow fluids, which, together with the alreadyexisting debility, seemed slowly to be ushering in dissolution. The promptness in opening the larynx evinced by the housesurgeon when asphyxia had actually commenced, was followed by a favourable termination.

The necessity of opening the larynx and trachea, for the relief of actual syphilitic ulceration and its consequences, is occasionally forced upon the surgeon, as our "Mirror" has several times illustrated. But an instance like the present, in which the operation has been performed for mercurio-syphilitic gangrene of the mouth, is somewhat rare.

We are indebted to Mr. J. J. M'Gregor, house-surgeon to the hospital, for the notes of the case:-

E. P - aged nineteen, an unfortunate girl, was admitted into the female venereal ward of the hospital on the 29 th of October, $1 \supset 58$, under the eare of Mr. de Méric. She was suffering from secondary symptoms, both legs being covered with papular eruptions. Her constitution, too, was much debilitated by privation and excesses. On questioning her closely, it was ascertained that she first contracted syphilis at Portsmouth, about four months previous to her admission; that she then came up to London, and became an in-patient of Guy's Hos213 